\title{
Nordiques
}

39 | 2020

Varia

\section{La tourbe, les trolls et le marché. Thorshavn à Tórshavn, ou William Heinesen dans les limbes de la culture coloniale canonique}

\section{Christian Bank Pedersen}

\author{
(2) OpenEdition \\ Journals \\ Édition électronique \\ URL : http://journals.openedition.org/nordiques/602 \\ DOI : 10.4000/nordiques.602 \\ ISSN : 2777-8479 \\ Éditeur : \\ Association Norden, Bibliothèque de Caen la mer \\ Référence électronique \\ Christian Bank Pedersen, "La tourbe, les trolls et le marché. Thorshavn à Tórshavn, ou William \\ Heinesen dans les limbes de la culture coloniale canonique », Nordiques [En ligne], 39| 2020, mis en \\ ligne le 01 novembre 2020, consulté le 13 mars 2021. URL : http://journals.openedition.org/nordiques/ \\ 602 ; DOI : https://doi.org/10.4000/nordiques.602
}

Ce document a été généré automatiquement le 13 mars 2021.

Nordiques 


\title{
La tourbe, les trolls et le marché. Thorshavn à Tórshavn, ou William Heinesen dans les limbes de la culture coloniale canonique
}

\author{
Christian Bank Pedersen
}

\section{À propos des colonies danoises jamais colonisées et du canon culturel du royaume}

1 Danmark og kolonierne, Le Danemark et les colonies, est le titre d'une somme de popularisation scientifique publiée à Copenhague en 2017. Rédigée par un collectif de spécialistes très majoritairement danois, elle est parue chez un éditeur reconnu pour ses ouvrages historiques. Elle contient cinq tomes : Le Danemark - Un pouvoir colonial, Groenland - La colonie arctique, L'Afrique de l'Ouest - Les forts de la Côte-de-l'Or, Les Antilles Sainte-Croix, Saint-Thomas et Saint-Jean et L'Inde - Tranquebar, Serampore et les îles Nicobar ${ }^{1}$. Faut-il en déduire que le royaume du Danemark n'a jamais colonisé la Norvège, ni l'Islande ou encore les îles Féroé ? Oui. D'abord, ces territoires sont entrés sous tutelle danoise en 1380, c'est-à-dire un bon siècle avant le début de ce qui est d'ordinaire considéré comme la véritable période du colonialisme européen moderne, faisant suite aux «Grandes découvertes » à partir de la fin $\mathrm{du} \mathrm{XV}^{\mathrm{e}}$. En outre, ce que découvrent les "Grandes découvertes» ce sont des populations rapidement catégorisées et traitées comme ethniquement et culturellement différentes de l'homme européen. Ce dernier aspect semble en effet disqualifier d'office les Norvégiens, les Islandais et les Féroïens en tant qu'historiquement colonisables par les Danois, compte tenu de la grande proximité sociale, culturelle et linguistique qui caractérise les Scandinaves depuis l'âge viking, ainsi que de l'absence - au cours de la longue période de domination danoise sur ces territoires - de toute violence étatique organisée utilisée à l'encontre de leurs habitants, parce que Norvégiens, Islandais ou Féroïens². 
2 Au printemps 2005, le Ministère de la culture danois crée sept comités couvrant chacun un domaine de l'art et du design sous toutes leurs formes, et ce, dans le but d'élaborer un « canon culturel » officiel du pays. Un an plus tard, en avril 2006, ces sept comités composés d'experts en architecture, arts plastiques, design et artisanat, cinéma, littérature, musique et arts de la scène - publient les résultats de leurs réflexions. Parmi les « 96 œuvres uniques de l'héritage culturel danois » qui en constituent alors le canon figure la comédie Jeppe på bjerget, Jeppe du Mont, dont la première représentation eut lieu à Copenhague fin 1722. En quoi cette pièce est-elle canonique? Par son statut de "grande et dangereuse comédie, qui ouvre une brèche à la mentalité populaire danoise " ${ }^{3}$. L'auteur de la comédie est Ludvig Holberg, dramaturge, philosophe et essayiste norvégien né à Bergen en 1684 et mort à Copenhague en 1754, laissant derrière lui une vaste production entièrement rédigée en danois. Aucune œuvre de l'écrivain et graphiste féroïen William Heinesen (1900-1991) n'est en revanche représentée dans le Kulturkanon. Pourtant, il est généralement admis qu'il compte parmi les tout premiers romanciers de langue danoise du $\mathrm{XX}^{\mathrm{e}}$ siècle. Quelle est dans ce contexte la différence entre Holberg et Heinesen? Elle est historique, évidemment, Holberg étant antérieur à la Révolution française et à la pensée romantique du peuple et de la nation, Heinesen postérieur à l'une et à l'autre. Par conséquent, ce qui les sépare est notamment l'histoire de la lente évolution des États-nations au XIX ${ }^{\mathrm{e}}$ siècle et donc de l'idée de l'identité culturelle nationale liée à leur constitution ${ }^{4}$. Holberg ne pouvait pas être nationaliste. Heinesen, comme on le verra, refusait de l'être. Pour Holberg, la Norvège n'était pas un thème en soi. Heinesen ne traite que des îles Féroé. Le premier accède au Canon culturel danois parce qu'il a écrit - n'ayant pas eu d'autre choix, en tant qu'auteur norvégien au XVIII siècle - dans la langue du pouvoir politique central de son époque. Le second n'y a pas droit de cité parce qu'il a choisi, en tant qu'écrivain féroïen, d'écrire dans la langue dominante de sa sphère culturelle. Cependant, ce n'est que récemment que leurs itinéraires se sont ainsi séparés, à savoir dans la période d'après-guerre et donc au cours du processus de décolonisation qui s'y déroule, processus ouvrant également la voie - sur le plan intellectuel - aux réflexions du postcolonialisme issu des cultural studies américaines dans les années $1980^{5}$. Reste le fait curieux qu'aucun des deux auteurs n'ait jamais habité un territoire colonisé par le royaume du Danemark ${ }^{6}$. Reste également la question de l'impact dans ce contexte du débat, parfois virulent, qui s'ouvre au Danemark dans ces mêmes années 1980 suite aux premières grandes vagues d'immigration non occidentale - d'origine encore postcoloniale - qui touchent alors le pays. Nous y reviendrons.

3 Notons d'abord que le Canon culturel danois regroupe effectivement 96 cuvres, et non 96 créateurs, architectes, compositeurs, auteurs, dessinateurs, peintres, etc. Cela est, entre autres, dû au fait que certaines de ces œuvres ne peuvent raisonnablement être attribuées à un quelconque individu. C'est le cas, à titre d'exemple, pour le "Char du soleil de Trundholm », figure en bronze datant de $1400 \mathrm{av}$. J-C. - quelques 2400 ans avant l'une des premières mentions du « Danemark » en tant qu'entité politique, sur la grande pierre de Jelling, érigée vers 980 - et le bateau viking « Skuldelev 2, l'étalon de mer de Glendalough », construit vers 1042 près de Dublin . En outre, par « œuvre » il faut clairement entendre production culturelle dans un sens très large - mais jamais définie -, étant donné que le Kulturkanon englobe des artefacts aussi divers que le "Cimetière de Mariebjerg ", établi entre 1925 et 1935 par le paysagiste Gudmund Nyeland Brandt, «La roue de chaise Kevi », inventée par l'architecte Jørgen Rasmussen en 1965, Ou bien ou bien de Søren Kierkegaard, publié en 1843, et les happenings 
critiques du capitalisme de "L'armée des Pères Noël », réalisés dans les années 1970 - le tout en passant par «Le pont de l'Est » liant l'île de Fionie à celle de Seeland, érigé entre 1991 et $1998^{8}$. Notons également la présence dans le Canon culturel de deux œuvres dont l'appartenance nationale pourrait être qualifiée de chiasmatique l'une par rapport à l'autre, en ce qui concerne le statut d'étranger de leurs créateurs : dans les années 1760, l'architecte français Nicolas-Henri Jardin (1720-1799) mène à bien une profonde restauration - et restructuration - d'un manoir de la Renaissance danoise, situé à Glorup sur l'̂̂le de Fionie. Le résultat en est un manoir de style baroque, «Le manoir de Glorup ", dont les lignes strictes suivent les idéaux français de l'époque, le XVIII ${ }^{e}$. Deux siècles plus tard, un architecte danois, Jørn Utzon (1918-2008), dessine les plans de l'Opéra de Sydney, l'un des monuments les plus iconiques de l'époque contemporaine. En 2006, ces deux œuvres entrent donc dans le Kulturkanon danois, catégorie architecture 9 . On pourrait essayer d'expliquer - et ainsi justifier - cette étrange coprésence en constatant que le premier des deux créateurs, Jardin, est antérieur à l'époque romantique tandis que le second, Utzon, est postérieur à cette période décisive par rapport à la conception moderne de l'artiste et de son appartenance culturelle. Néanmoins, si l'Opéra de Sydney est danois, le manoir de Glorup est français ${ }^{10}$. Bref, dans quel univers «La roue de chaise Kevi » est-elle davantage canonique de la culture danoise que les romans de William Heinesen? Dans celui du retour de l'héritage national romantique du tournant du siècle 2000.

La mainmise linguistique - et ainsi la domination politique et culturelle - qu'exerce le royaume du Danemark sur les territoires scandinaves qu'il gouverne à partir de la fin du XIV ${ }^{e}$ siècle se trouve renforcée par l'instauration de la Réforme protestante dans les années $1530^{11}$ : au Danemark, d'abord, l'arrivée au pouvoir du luthérien Christian III (1536-1559) signifie aussi la mise en place de la Réforme, officialisée par le dénommé

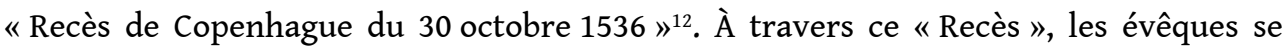
voient démis de leurs fonctions et les biens et terres de l'Église catholique annexés au profit de la royauté, qui prend par la même occasion souverainement le contrôle de l'institution ecclésiastique en l'écartant du pouvoir politique. En accord avec l'enseignement de Luther, le statut de la langue danoise est également revalorisé, c'està-dire en tant que langue vernaculaire par laquelle allait désormais passer la parole divine - d'abord à l'aide de sermons, de psaumes et du Petit catéchisme, puis de la première traduction intégrale de la Bible, datant de 1550 - afin de transformer les Danois en bons chrétiens évangéliques et en sujets obéissants ${ }^{13}$.

Le dimanche $1^{\text {er }}$ avril 1537, le jour de Pâques, Olav Engelbrektsson (1480-1538), archevêque de Nidaros et président du Riksråd, le Conseil du royaume norvégien, quitte la Norvège, ayant perdu deux combats décisifs face au roi danois, à savoir celui du maintien de l'Église catholique dans son pays et celui de l'indépendance de ce dernier ${ }^{14}$. Avec l'instauration de la Réforme par Christian III commencent alors pour la Norvège, 277 ans de totale domination politique et culturelle danoise sur son territoire : comme au Danemark, les terres et biens de l'église reviennent à la royauté, qui dissout en outre le Riksråd norvégien, faisant par là même de son voisin un État satellite dont la langue locale écrite sera officiellement écartée et ce, au point de disparaître au cours des siècles suivants.

Plus loin à l'ouest, dans l'océan Atlantique Nord, la situation est fortement similaire : en 1538, le dernier évêque catholique féroïen, Amundur Ólavsson, est relevé de ses fonctions et déporté au Danemark. S'ensuit comme ailleurs la mainmise de la couronne 
danoise sur les terres catholiques, ainsi qu'une danisation radicale des îles, le féroïen étant à partir de là interdit d'usage dans la liturgie, le système judiciaire et les documents officiels en général. Jusqu'à la fin du XIX siècle, le féroïen ne survit qu'en tant que langue orale. Dotées d'une autonomie relative depuis 1948, les îles Féroé font encore aujourd'hui partie de rigsfellesskabet, la "communauté du royaume", rassemblant également le Danemark propre et le Groenland dans ce qui est le royaume du Danemark comme État souverain unitaire. Par conséquent, le danois y possède toujours le statut de langue officielle secondaire ${ }^{15}$. En revanche, cette langue secondaire des Féroïens n'entre pas dans la culture danoise.

7 Dans les années 1530, Jón Arason (env. 1479-1550) installe la première imprimerie en Islande. Cette initiative du dernier évêque catholique du pays a largement contribué au maintien de la culture écrite islandaise, même après l'instauration - très conflictuelle de la Réforme sur le territoire. Suite à la suppression de l'église catholique en Norvège dont dépendaient les évêchés en Islande -, Christian III exige, en vain, la ratification du nouvel ordre ecclésiastique par l'Althing. La résistance islandaise sera menée par Arason, évêque de Hólar, et de son homologue de l'évêché de Skálholt, Ögmundur Pálsson (env. 1473-1541). Après la mort de Pálsson - forcé de se retirer en 1540, puis arrêté et déporté l'année suivante, celui-ci décède au cours du voyage vers le Danemark -, Arason essaie de mettre la main sur l'évêché de son collègue disparu. Déclaré hors-laloi par Christian III, il est finalement décapité en compagnie de ses deux fils le 7 novembre 1550, à Skálholt. À partir de là, la situation de l'Islande sera semblable à celle de la Norvège et des îles Féroé : soumise à une royauté danoise qui devient par la Réforme le plus grand propriétaire terrien du pays, l'île dépendra parfaitement des institutions politico-religieuses de son maître ${ }^{16}$.

Prétendre que le royaume de Danemark n'a pas agi en colonisateur lors de l'instauration de la Réforme sur les territoires de ses dépendances scandinaves à la fin de la première moitié du XVI ${ }^{e}$ siècle est au mieux un signe de mauvaise foi ${ }^{17}$. Les conséquences socio-culturelles pour ces territoires de cette transformation à la fois religieuse et politique - ainsi que de l'impérialisme linguistique qui l'accompagnait sont historiquement déterminantes. Le protestantisme luthérien a-t-il façonné les sociétés norvégienne, féroïenne et islandaise ? Indéniablement. La culture écrite de ces pays a-t-elle été marquée par un assujettissement catégorique - notamment en Norvège et aux îles Féroé - à la langue danoise, et ce, dans la vie culturelle, au niveau de l'administration étatique et dans le système éducatif? Sans aucun doute. Et le protestantisme luthérien ainsi que la pénétration massive du danois sur ces territoires sont les faits d'une décision souverainement coloniale de la part du royaume de Danemark, en l'occurrence de Christian III et de son gouvernement. Certes, les Scandinaves sont historiquement - «ethniquement", géographiquement, culturellement et socialement - proches. Ainsi, les ambitions géopolitiques - ambitions religieuses incluses - de la royauté danoise vers le milieu du $\mathrm{XVI}^{\mathrm{e}}$ siècle visent effectivement la domination telle quelle, plutôt que la soumission de peuples considérés comme ethniquement autres. Mais là où il y a différence, il y a altérité. Et, si le royaume de Danemark s'efforce tant d'imposer le danois sur les territoires scandinaves qu'il dominera fermement à partir de cette époque, ce n'est sûrement pas pour éradiquer un écart linguistique - et par conséquent culturel et social - qui n'aurait aucune réalité. Il existe bel et bien un colonialisme intra-nordique et le royaume de Danemark en est un représentant notable - avec sa capitale Copenhague à une distance géographique et 
administrative non négligeable d'un grand nombre de districts norvégiens, islandais et féroïens perdus dans l'obscurité historique hivernale.

Depuis 1814, aucun auteur norvégien de langue «danoise » - aucun auteur en activité après cette date, s'entend - n'entre en principe dans l'histoire de la littérature écrite en cette langue. Il ne viendrait à l'esprit de personne de considérer Henrik Ibsen comme un auteur danois, bien qu'il ait rédigé son œuvre en riksmål et fait paraître ses pièces dans l'ancienne capitale coloniale Copenhague, chez l'inévitable éditeur Gyldendal, dirigé par le légendaire Frederik Hegel. Il n'avait pas vraiment le choix, comme d'autres auteurs norvégiens du XIX ${ }^{\mathrm{e}}$ siècle, tant les conséquences de l'hégémonie linguistique danoise, et donc de l'influence de l'institution littéraire concentrée à Copenhague, se faisaient encore ressentir ${ }^{18}$.

Plus tard, au cours de la première moitié du XX $\mathrm{X}^{\mathrm{e}}$ siècle, un écrivain comme l'Islandais Gunnar Gunnarsson peut encore figurer dans divers survols critiques de la littérature danoise contemporaine, en tant que le plus célèbre et le plus populaire des auteurs de l'île ayant rédigé leurs œuvres en danois, partiellement ou intégralement ${ }^{19}$. Mais Gunnarsson brille généralement par son absence dans les histoires de la littérature danoise, surtout celles publiées après 1944, l'année de l'indépendance islandaise. Dans celles-ci se trouvent en revanche les auteurs féroïens William Heinesen et JørgenFrantz Jacobsen et ce, au même niveau que leurs collègues danois. En fait, pendant longtemps ils ne sont guère considérés comme des auteurs féroïens, à en croire l'index de l'un des plus grands succès de vente de l'édition danoise des années 1960, Dansk litteraturhistorie, ouvrage collectif dirigé par Gustav Albeck et F. J. Billeskov Jansen et publié en quatre tomes au milieu de la décennie. Dans cet index, la nationalité est signalée uniquement pour les écrivains étrangers, et les noms de William Heinesen et de Jørgen-Frantz Jacobsen ne sont suivis d'aucune mention de leur origine. Ce sont donc des auteurs danois, présentés dans une histoire de la littérature danoise ${ }^{20}$. Ensuite, tous les deux apparaissent en tant qu'auteurs féroïens - ou, dans le cas de Jacobsen, dano-féroïen - dans toutes les représentations décisives de cette même histoire littéraire au cours des dernières décennies $\mathrm{du} \mathrm{XX}^{\mathrm{e}}$ siècle, et au-delà : dans les neufs tomes du grand essai d'inspiration marxiste Dansk litteraturhistorie publié par Gyldendal entre 1984 et 1985 et dans les cinq volumes de l'ouvrage Dansk litteraturs historie valorisant davantage la réciprocité entre la littérature danoise et l'histoire culturelle européenne, parus chez le même éditeur de 2006 à 2009, en passant par le dictionnaire d'auteurs danois Litteraturens stemmer sorti aux éditions Gad en $1999^{21}$.

11 Limitons-nous à William Heinesen. Son apparition dans Dansk litteraturs historie éditée par Gyldendal entre 2006 et 2009, et dirigée par Klaus P. Mortensen et May Schack, peut être considérée comme une réaction à sa disparition de l'histoire dans Hovedsporet, $L a$ trace principale, publiée par la même maison d'édition en 2005, un an avant la parution de cette première grande Histoire de la littérature danoise du XXI ${ }^{\mathrm{e}}$ siècle; réaction due certainement aussi à son absence du canon littéraire danois de 2006. Il n'y a rien « de plus actuel, rien de plus intensément contemporain que les "racines culturelles" ", écrit le philologue italien Maurizio Bettini dans son ouvrage Contre les racines. En effet, la tradition se crée toujours au présent, ce "présent " qui ne cesse de la redire et de l'enseigner ${ }^{22}$. Dans l'univers danois, l'histoire de cette histoire - du présent moderne qui dit la tradition - commence au XIX ${ }^{e}$ siècle, notamment chez le père du romantisme national danois N. F. S. Grundtvig (1783-1872) pour qui la "danité ", danskheden, était constituée par un «trèfle à quatre feuilles", ces feuilles étant «Konge og folk, 
fædreland og modersmål ", "Roi et peuple, patrie et langue maternelle ", comme l'auteur le signale dans son petit ouvrage Le trèfle à quatre feuilles danois ou la danité considérée de manière partiale ${ }^{23}$. En 1836, l'année où Grundtvig précise ainsi la nature de ce «trèfle" national - et il s'agit évidemment pour lui d'une entité naturelle, par laquelle se dévoile aussi la secrète cohésion du christianisme et du passé païen nordique -, l'auteur connait bien le travail du philosophe préromantique allemand J. G. Herder (1744-1803) et la conception du peuple et de la nation en tant qu'unité organique - et ainsi dynamique - qu'il propose. Dans les inachevées Ideen zur Philosophie der Geschichte der Menschheit, Idées pour une philosophie de l'histoire de l'humanité, de 1784-91, Herder désigne justement l'histoire, la langue et la culture particulières de chaque peuple comme les forces fondatrices de cette unité24. Ainsi se crée aussi la tradition de la danskhed, « l'être-danois » ou la danité, en tant que la cohérence et la cohésion des productions culturelles portées par le peuple et sa langue à travers l'histoire. Mais cette tradition est en effet largement inventée, comme le montre par exemple le travail de cette autre création romantique, à savoir la folkloristique, sur les ballades populaires, les folkeviser ou Volkslieder: au début des années 1840, Svend Grundtvig (1824-1888) - fils de N. F. S. Grundtvig - commence l'œuvre de collection, d'édition, de recherche et d'enseignement qui constituera la «tradition » des folkeviser danoises dont la vie véritablement populaire était à ce moment-là à bout de souffle. Par là même, les efforts de Grundtvig signifient aussi l'arrêt de mort du Volksgeist qu'ils étaient censés sauver. Dans le même temps, le travail du folkloriste crée donc ce qu'il était censé simplement décrire : la cohésion et la cohérence à travers le temps. Le résultat en est Danmarks gamle folkeviser, Les ballades anciennes du Danemark, dont le premier tome fut publié en 1853. Tout se réalise à travers l'histoire, et tout est histoire. Pour cette raison, n'oublions pas que c'est à partir des pensées historique et esthétique du tournant du XVIII ${ }^{\mathrm{e}}$ au XIX ${ }^{\mathrm{e}}$ siècles que la professionnalisation de l'enseignement de ce qu'on appelle encore aujourd'hui la " culture générale » - l'histoire, la littérature, la philosophie, les arts, etc. - commence à s'établir, surtout au cours de la seconde moitié du XIX siècle, période pendant laquelle la bourgeoisie confirme sa position dominante, socialement et culturellement. Cet enseignement constitue par conséquent un élément important de la Bildung, c'est-à-dire de l'éducation, de la formation et de la socialisation. Au sud de la frontière danoise continentale, on voit la fondation des universités qui prônent, en principe, l'enseignement et la recherche libres. C'est la naissance de ce qu'on nomme le modèle humboldtien, ou l'université humboldtienne, d'après le philosophe et linguiste Wilhelm von Humboldt (1767-1835), fondateur de l'Université de Berlin. Ce modèle basé sur la pensée historique va également dominer le monde éducatif supérieur danois.

Dès l'instant où la pensée romantique fonde sa conception de la culture nationale - et donc, ultérieurement, de l'État-nation politique - sur l'idée de l'unité organique du peuple et de la nation que créent la langue et les productions culturelles à travers l'histoire, cette même pensée romantique est prise à son propre piège : si la culture d'un peuple se manifeste et se réalise par l'histoire, ce qui unifie est justement ce qui distingue, et vice-versa. À quel niveau? Au niveau de la langue et de son statut de fait social dans l'histoire : si les Danois sont unis historiquement par leur langue, c'est aussi parce qu'ils partagent une partie conséquente de l'évolution de cette langue avec les Féroïens, les Islandais, les Norvégiens et les Suédois - passés, actuels et futurs - et ce, grâce à une origine commune avec le scandinave médiéval ; et accessoirement à cause du colonialisme linguistique exercé ici et là par le royaume de Danemark à partir du 
$\mathrm{XVI}^{\mathrm{e}}$ siècle. Puis, on pourrait aller plus loin en arrière, compte tenu de l'importance primordiale de l'histoire : en compagnie de leurs frères linguistiques scandinaves, les Danois se distinguent des Allemands, des Anglais, voire des Indiens grâce à ce qui les fait ressembler à ces mêmes peuples, à savoir le développement des langues indoeuropéennes ${ }^{25}$. Un Danois contemporain a-t-il culturellement plus en commun avec un Indien qu'avec un Finlandais, ce dernier étant linguistiquement très éloigné de la famille des langues indo-européennes? Probablement pas. En tant qu'élément décisif de la conception de l'État-nation culturel et politique, le critère de la langue et de son histoire restera cependant toujours à double tranchant. Où commence cette histoire, au juste? Au moment où l'on réinvente ses débuts comme origine nationale, c'est-à-dire, dans l'histoire danoise, autour de 1800. Tant pis, en ce sens, pour les Féroïens et les Norvégiens du même XIX ${ }^{e}$ siècle, fatigués de la longue domination linguistique pratiquée par le royaume de Danemark. Il en est ainsi, historiquement.

Depuis les années 1980, le débat public danois le plus important - débat culturel, social et politique - tourne autour du vivre-ensemble entre les Danois dits « de souche » et les groupes d'immigrés de cultures différentes, surtout musulmane, groupes souvent constitués de réfugiés ayant fui les zones de conflit du Moyen-Orient qui ont déterminé la géopolitique mondiale des dernières décennies $\mathrm{du} \mathrm{XX}^{\mathrm{e}}$ siècle, ainsi que celle du début $\mathrm{du} \mathrm{XXI}^{\mathrm{e}}$. Souvent âpre, voire venimeux, ce débat s'est rapidement dirigé vers la question de la définition même de "l'identité nationale " danoise et des valeurs démocratiques, sociales et culturelles qu'elle porte - ou qu'elle devrait porter - vis-àvis des fremmede, ces "étrangers" souvent jugés incompatibles avec ces mêmes valeurs $^{26}$. Ainsi, il est donc aussi clairement lié à ce phénomène plus vaste encore dont fait partie le problème migratoire contemporain, à savoir la mondialisation.

Partout dans le monde, dans n'importe quelle ville d'une certaine taille - de Kiruna à Canberra en passant par Nuuk -, l'on peut entrer dans les franchises locales des mêmes enseignes multinationales et y trouver les mêmes cafés, sandwichs, vêtements et parfums, entre autres, dont les mêmes médias font la même publicité globale, diffusée sur des chaines émettant des programmes de téléréalité identiques. Pour les touristes, par exemple, tout éventuel sentiment de dépaysement éprouvé dans la localité de leur séjour se dissout à la porte d'entrée de ces endroits, sauf peut-être chez celles et ceux qui les considèrent en toute conscience - au second degré - comme des «non-lieux $»^{27}$. Je ne m'y attarderai pas de mon côté, cet aspect de la mondialisation - qu'on le dénomme « uniformisation » ou " homologation » culturelle - ayant déjà été étudié à la hauteur de son extension ${ }^{28}$. Le Kulturkanon danois est en partie l'expression d'un désir de bouclier local national contre cet universalisme des biens marchands culturels passant des applications informatiques aux tubes planétaires -, tout comme l'est par exemple la notion d'" exception culturelle», ou de "diversité culturelle», en tant qu'appliquée à la sphère française ${ }^{29}$ : la différence entre Copenhague et Paris se situe dans l'autrefois, notamment celui de la construction nationale du XIXe siècle qui établit largement notre conception de l'héritage culturel. Dans le sens d'une autre différenciation, le Canon culturel joue le rôle de repère identitaire vis-à-vis de l'immigration extra-européenne - mais pas seulement extra-européenne - dont le pays fait l'expérience depuis les dernières décennies $\mathrm{du} \mathrm{XX}^{\mathrm{e}}$ siècle. Que signifie «l'êtredanois ", c'est-à-dire la "danité " - danskheden -, par rapport à cette étrange étrangère que l'on perçoit dans la culture musulmane venue avec les réfugiés et immigrés du Moyen-Orient? 
15 Aujourd'hui, les cultures nationales - peut-être surtout les identités culturelles nationales occidentales - se sentent menacées par la mondialisation et les flux migratoires ${ }^{30}$. Cette menace ressentie pourrait contenir un élément de Nachträglichkeit, d'après-coup ${ }^{31}$ : si l'on doit tant s'acharner à définir son identité, c'est peut-être parce qu'on la sait déjà perdue. Comme le signale l'égyptologue Jan Assmann dans son ouvrage Das kulturelle Gedächtnis, La mémoire culturelle, le canon répond en principe à la question: "Wonach sollen wir uns richten ?", «À quoi devons-nous nous conformer? $\aleph^{32}$. Canon signifie mesure au sens de fil conducteur ${ }^{33}$. Existe-t-il un fil conducteur pour une culture nationale comme la culture danoise? Si oui, il est tortueux. Un canon culturel national ne semble plus avoir lieu d'être - aussi dans le sens où il ne trouve plus de lieu pour se situer véritablement. D'où le désir d'en créer un.

16 Notons dans cette perspective une scission particulière à l'intérieur même du Canon culturel danois: la publication de l'ouvrage Kulturkanon a été subventionnée par «Dronning Margrethes og Prins Henriks Fond ", «La fondation de la Reine Margrethe et du Prince consort Henrik $»^{34}$. Ainsi, la maison royale danoise a soutenu la parution d'un Canon culturel qui n'est pas et qui ne peut pas être celui du royaume de Danemark, royaume composé du Danemark propre, des îles Féroé et du Groenland. L'identité nationale que fait valoir le canon en question constitue donc une schizophrénie culturelle dans le sens original du terme. Ce fractionnement de l'esprit signale une détresse romantique de l'identité qui relègue étrangement la langue danoise au rang des critères de sélection non décisifs. Tórshavn, le nom de la capitale féroïenne, s'écrit Thorshavn au Danemark et dans l'œuvre de William Heinesen. Voilà une des raisons pour lesquelles l'auteur n'entre pas dans le canon littéraire officiel de ce colonisateur qui à ses propres yeux étatiques n'en a jamais été un.

\section{Ce lieu qui en cache d'autres : Thorshavn à Tórshavn chez Heinesen}

17 "Je ne suis jamais allé au-delà de Thorshavn et des îles Féroé », indique William Heinesen dans un entretien avec le quotidien danois Information en janvier 1980, avant d'ajouter: «Cela dit, je trouve que tout ce dont il vaut la peine de parler se déroule ici $»^{35}$. Tout a lieu ici, dans le minuscule archipel des Féroé. Mais de quoi vaut-il alors la peine de parler?

18 Ayant vécu et étudié à Copenhague - la ville qui constitue le centre de la périphérie dont fait partie l'auteur -, Heinesen est bien allé «au-delà de Thorshavn et des îles Féroé ». En réalité, c'est ainsi qu'il a atteint cette vue de l'extérieur qui lui permet de ne jamais quitter son lieu natal : il fait référence, bien sûr, à un choix artistique, pas à des événements plus ou moins contingents de son parcours personnel. Il constate donc le résultat d'une décision au niveau de son œuvre. Puis, il émet un jugement subjectif : "Tout ce dont il vaut la peine de parler se déroule» dans l'ici de Thorshavn et des Féroé. Le local est l'universel. Ou plutôt, le local est universel précisément parce qu'il n'est jamais l'universel, au singulier défini.

19 Cet universel de la localité féroïenne est dans l'œuvre de Heinesen lié à une date spécifique au milieu du XIX ${ }^{e}$ siècle : en 1856, le royaume de Danemark décide d'abolir le monopole commercial sur les îles Féroé, et ce, pour cause de situation sociale misérable dans l'archipel. Jusque-là, ce monopole était détenu par « le Commerce royal féroïen », 
institution économique et politique danoise ayant maintenu les Féroïens dans un isolement total et une pauvreté ahurissante pendant des siècles. En 1856, la suppression du monopole danois sur la vie économique, politique et par conséquent culturelle féroïenne met donc fin à l'époque féodale. En 1856, les îles Féroé s'évadent du Moyen Âge et entrent ainsi sans véritable intermédiaire dans la modernité.

Il va sans dire que les choses ne sont pas aussi simples. Entre autres parce que les dates ne sont pas toute l'histoire, comme l'a noté Claude Lévi-Strauss ${ }^{36}$. Néanmoins, l'année 1856 joue pour les Féroé un rôle comparable à celui que porte dans l'histoire de la France et de l'Europe celle de 1789, l'année de l'avènement des Lumières politiques et ainsi de l'ouverture de l'histoire contemporaine : il y a un avant et un après, il y a le passage - certes balbutiant et contesté - d'un ordre politique et social féodal à un dispositif démocratique libéral, libéral aussi dans le sens économique du terme, ouvrant définitivement la voie à l'industrialisation. Mais la comparaison s'arrête là, à ce niveau local féroïen : tandis que la Révolution française de 1789 a eu des répercussions politiques, sociales et culturelles qui perdurent encore aujourd'hui, la suppression en $1856 \mathrm{du}$ monopole commercial sur le minime territoire atlantique que constituent les îles Féroé n'a eu des conséquences que pour le minime territoire atlantique constitué par les îles Féroé. En quoi consiste donc l'envergure d'un territoire, et d'un événement historique ? Dans les années 1850, les dix-huit îles féroïennes - plus petites les unes que les autres - sont habitées par sept à huit mille personnes ${ }^{37}$. Par rapport à leur maître danois, elles rayonnent par leur modicité. Par rapport à l'Europe vis-à-vis de laquelle le royaume de Danemark n'a lui-même que de peu de poids, elles se trouvent à l'extrême limite de la simple visibilité.

21 À en croire l'auteur féroïen William Heinesen, c'est en cela que réside l'excellence de leur petitesse, voire leur exemplarité. Né en 1900 et mort en 1991, Heinesen couvre à plus d'un égard le $\mathrm{XX}^{\mathrm{e}}$ siècle du début à la fin, que ce soit en tant que romancier, auteur de nouvelles et de mémoires, ou bien en sa capacité de poète, essayiste, peintre et graphiste. Son œuvre est tout aussi fermement ancrée dans l'art européen moderne l'expressionnisme en poésie et en peinture, le réalisme social et historique de l'écriture prosaïque - que marquée par la particularité de l'histoire et de la culture féroïennes ${ }^{38}$. En ce qui concerne cette dernière particularité, William Heinesen revient encore et toujours - de façon oblique ou de front - à 1856, l'année de la suppression du «Monopole royal ", quand «le temps présent " commence «peu à peu à chasser le Moyen Âge féroïen, démesurément long et tenace ", comme il est dit dans la nouvelle «Belsmanden", "L'hôte diabolique», du recueil Fortcellinger fra Thorshavn, Récits de Tórshavn, publié en $1973^{39}$. C'est le $1^{\mathrm{er}}$ janvier de cette année que le royaume de Danemark laisse officiellement sortir les Féroïens de leur infortune féodale.

Tórshavn, la capitale féroïenne, est Thorshavn, un petit port sous tutelle historique danoise. C'est ici que tout se passe. C'est ici que l'époque médiévale cède la place à la modernité lorsque la pêche industrialisée prendra la relève, à partir de la dernière moitié du XIX ${ }^{e}$ siècle, de l'agriculture en mode féodal. C'est le lieu de tous les lieux: l'omphalos, l'ombilic de l'univers, "le centre absolu du monde». C'est un vivier cosmopolite et un theatrum mundi singulier. En même temps, Thorshavn n'est qu' « une cité obscure aux confins de la terre ! - - ». C'est « la capitale la plus petite du monde » - qui reste pourtant dans les souvenirs d'enfance « une grande ville, oui, une ville de renommée mondiale $»^{40}$. 
23 La ville natale de William Heinesen possède une certaine grandeur de l'insignifiance, puisqu'elle est le centre et la périphérie - ou bien le centre de la périphérie, voire la périphérie du centre ${ }^{41}$. Elle est éminemment ancienne, millénaire, et tout à fait récente. Elle est mythe, hors du temps, et elle n'est rien sinon historique. Tout est dans la dénomination: Thorshavn est un nom propre composé d'un nom propre - « Thor », qui en tant que nom d'une divinité certifie l'intemporelle actualité de l'imaginaire - et d'un nom commun : "havn ", qui se réfère nécessairement à une existence sociohistorique. Ainsi, Thorshavn, le «Port de Thor », est chez Heinesen le centre absolu symbolique d'un monde sans centre puisque les lieux des hommes - leurs bourgades, hameaux, villages, cités et autres villes, petites et grandes - se situent toujours, peu importe leur localisation, à l'intersection de l'imaginaire et du réel, du mythe et de l'histoire. Comme ici, aux îles Féroé, à Thorshavn, cette capitale dont le nom établit à lui seul une mythologie et une vie sociale : Thor, le puissant dieu guerrier possède un port parmi les mortels. Ce port constitue le suprême lieu d'échange - d'arrivées et de départs, de débuts et de fins - d'un petit peuple atlantique. Il est donc le lieu par excellence de l'histoire de ce même peuple. Mais il l'est ici en danois, langue qui écarte la langue écrite du peuple en question.

Voici l'incipit de l'essai autobiographique - qui est en même temps un essai biographique de la ville - intitulé «Småstad og Babel », «Bourgade et Babel », publié pour la première fois en 1967 dans le recueil Kur mod onde ånder, Cure contre les mauvais esprits.

Thorshavn, ma ville natale, ne se distingue ni par sa beauté extérieure ni par une position géographique étrange ou des accomplissements extraordinaires. C'est juste un bout de bourgade entre la mer et la lande rocheuse. Mais cette bourgade n'est pas seulement la capitale de tout un petit archipel, et la plus grande ville dans un rayon de plusieurs centaines de kilomètres; elle peut également, comme n'importe quel autre endroit sur la planète où des hommes naissent et grandissent, se proclamer l'ombilic du monde en tant que tel. C'était ici que le soleil et la lune se montrèrent pour la première fois, ici est le lieu [her er stedet] où furent créés la nuit et le jour. ${ }^{42}$

Thorshavn, la capitale qui unifie en son nom la mythologie et l'histoire, a donc vocation à ne pas être éternellement remarquable. La ville de William Heinesen partage ce trait distinctif avec tous les autres lieux qui portent la marque d'une présence humaine. Il n'y pas de "position géographique étrange » parce que toutes les positions géographiques sont en principe également étranges, c'est-à-dire au même niveau d'étrangeté. Thorshavn vaut New York. À Thorshavn ou à New York, nous sommes peu de chose, et ce peu de chose est tout. Thorshavn n'est rien, rien que « l'ombilic du monde en tant que tel ».

Dans quelles perspectives peut-on donc selon Heinesen considérer la capitale des îles Féroé ? Dans toutes. "Thorshavn », le premier mot de l'essai « Bourgade et Babel», est évidemment une ville identifiable, située sur la carte du monde. Ainsi, elle peut faire l'objet d'une étude géographique, ne serait-ce que pour signaler sa "position" nullement "étrange " - "position » qu'il est par ailleurs impossible de définir d'un point de vue philosophique. Étant la «ville natale» d'un certain nombre d'hommes, elle ouvre aussi nécessairement des réflexions biographiques, en l'occurrence les considérations autobiographiques de son auteur le plus connu, William Heinesen. Ensuite, elle ne semble pas briller "par sa beauté extérieure" et elle se laisse par conséquent soumettre à un jugement esthétique, comme n'importe quelle autre ville. En 
outre, les Féroïens semblent mener une vie historique étonnamment discrète, leur capitale n'étant pas non plus connue pour ses "accomplissements extraordinaires». Toutefois, la ville de Thorshavn est bien sûr aussi à considérer dans la perspective de l'histoire, que celle-ci soit sociale, culturelle ou géopolitique. Faute de mieux, on signalera éventuellement que Thorshavn entre dans l'histoire pour s'y faire oublier.

Par ailleurs, la capitale féroïenne égale «n'importe quel autre endroit sur la planète où des hommes naissent et grandissent ». Ainsi, elle s'inscrit naturellement dans une perspective anthropologique: "C'était ici que le soleil et la lune se montrèrent pour la première fois, ici est le lieu où furent créés la nuit et le jour ». Ici est le lieu, «her er stedet ", puisque c'est toujours ici qu'on est là ${ }^{43}$ : le lieu est toujours un ici. Ce lieu, on le partage avec toutes et tous, même celles et ceux qui ne sont pas d'ici. William Heinesen est de Thorshavn par hasard. Être Féroïen ne veut rien dire en soi. Mais Heinesen l'est. Par conséquent, c'est à Thorshavn qu'est situé le centre imaginaire de la planète. Parce que Thorshavn, c'est nous, «bourgade » et "Babel » que nous sommes où que nous soyons. Une "bourgade» qui est toujours dotée d'une histoire locale, et ce lieu «Babel » qui restera de son côté indéfiniment le symbole mythologique de la longue et durable confusion que constitue l'histoire de l'homme - d'un point de vue judéochrétien. Le singulier est pluriel.

L'incipit de l'essai « Bourgade et Babel » couvre en ce sens une vaste distance, distance que l'on peut parcourir sans entreprendre le moindre déplacement, puisqu'elle est intérieure au lieu dont il est question. En fin de compte, elle est intérieure à n'importe quel lieu "sur la planète où des hommes naissent et grandissent ", avec, à nouveau, la formule de Heinesen. C'est la distance qui sépare une «bourgade» de «Babel». De cette manière, nous sommes toujours déjà aux îles Féroé, à Thorshavn, tout comme les Féroïens se trouvent parmi nous : l'histoire est forcément anthropologique, rappelle implicitement William Heinesen, tout en étant conscient du fait que l'histoire en tant que science moderne est intimement liée à la construction des États-nations - dont les îles Féroé ne font toujours pas partie - avec lesquels elle se développe à la fin du $\mathrm{XIX}^{\mathrm{e}}$ siècle, entre autres à travers le travail de Leopold von Ranke en Prusse - ou en Allemagne, après 1871 -, de Jules Michelet en France et de Kristian Erslev au Danemark, qui regardent tous le passé d'un œil national ${ }^{44}$. Heinesen, l'auteur qui n'est jamais allé au-delà de Thorshavn et des Féroé, s'efforce pour sa part d'«anthropologiser " l'histoire afin de la dénationaliser ${ }^{45}$.

Dans le roman historique Le bon espoir, paru en 1964, on suit le récit des combats théologiques, politiques et sociaux du pasteur et narrateur Peder Børresen, luthérien tiraillé entre son penchant pour la déchéance alcoolisée et les inévitables méandres de la pénitence. Cette histoire est prétendument racontée dans une suite de lettres à "Jonas ", ami et confrère de Børresen, entre avril 1669 et juillet 1670, dates qui nous emmènent à la fois au début de l'époque de l'absolutisme danois, instauré en 1660, et au seuil des Lumières. Envoyé dans cet exil atlantique par l'Église à cause de son mode de vie médiocrement protestant, Peder Børresen fait la connaissance d'un territoire sinistre, frappé jour et nuit par la pluie et le vent, et dans un état social, politique et juridique effroyable : à ce moment-là vers la fin du XVII siècle, la royauté danoise a abandonné les îles Féroé entre les mains de la famille aristocrate Gabel - notamment le gouverneur Christoffer Gabel (1617-1673) - qui laisse ses serviteurs gérer cette colonie comme bon leur semble, dans le seul but d'en tirer profit ${ }^{46}$. Par conséquent, le pasteur Børresen doit se battre, constamment. Il se bat contre les petits monstres imaginaires 
de la superstition populaire qui détecte des incubes à tout coin de rue. Et il s'insurge contre les causes sociales de ces multiples imaginations et autres égarements hérétiques, c'est-à-dire l'injustice et la pauvreté, véritables maîtres du lieu. Lisons deux passages qui traitent de la lamentable localité dans laquelle Peder Børresen a eu le malheur d'atterrir.

[...] la petite cité, le Port [Havnen], sur sa pointe de terre dans un voile de fumée bleue de tourbe, une drôle de construction de troll à contempler, comme une carrière, habitée par des êtres souterrains.

[...] tout en bas, presque impossible à distinguer des alentours pierreux, se trouvait sur sa pointe de terre la petite cité d'où j'étais venu, comme un tertre parmi d'autres. ${ }^{47}$

30 Thor a quitté les lieux. Il ne reste que le Port, nom propre sous forme de nom commun au défini : «Havnen ». Apparemment, le mythe s'en est allé, ne laissant aux Féroïens qu'un port, le Port, c'est-à-dire un lieu réduit, à première vue, à sa simple fonction socio-économique. Séparée de sa divinité médiévale par une synecdoque, la capitale féroïenne semble se fondre dans le paysage : c'est un petit bout de culture difficile à distinguer de son environnement naturel, un tas de pierres dans le rocher, un tertre quelconque parmi d'autres. Pourtant, ceci est encore Thorshavn, puisque chez Heinesen cette minime cité est toujours la partie qui représente le tout: un port est un lieu frontalier par excellence - entre terre et mer - et le port, nom commun, qu'est Thorshavn, nom propre, se situe "sur sa pointe de terre " à l'exacte intersection du générique et du singulier, de ce qui est effectivement commun à tous les lieux et de ce qui est propre à l'ici spécifique.

31 En outre, le pasteur Børresen a beau la combattre - en accord avec la réglementation luthérienne -, la pénible superstition populaire persiste, avec ses étranges lutins et autres trolls, qui devraient, selon lui, être renvoyés dans le passé du passé, c'est-à-dire à l'époque révolue de l'imaginaire païen. Seulement, ce passé n'est pas passé. Il est présent. Lisons à nouveau les mots du pasteur-narrateur au sujet du Port: «[...] la petite cité, le Port [Havnen], sur sa pointe de terre dans un voile de fumée bleue de tourbe, une drôle de construction de troll à contempler, comme une carrière, habitée par des êtres souterrains ». À travers ce propos, nous voyons où se situe réellement l'imaginaire: le "voile de fumée bleue de tourbe» qui enveloppe la ville et la comparaison qui l'assimile à « une carrière » sont les signes de la vie sociale et pratique contemporaine des Féroïens dans la ville de Thorshavn. En même temps, la capitale des Féroé est "une drôle de construction de troll à contempler ", une bâtisse de troll " habitée par des êtres souterrains ", et Thorshavn est donc encore et toujours portée par l'imaginaire d'autrefois, par l'imaginaire médiéval. Ainsi, l'irréel du passé loge dans le réel du présent, et l'imaginaire du mythe - qui n'est en soi nullement féroïen persiste dans l'univers social actuel de cette localité, précisément. Le mythe est donc chez Heinesen tout sauf intemporel, dans le sens où son imaginaire se situe et se réalise dans la pratique du quotidien. Oui, la pratique du quotidien est l'imaginaire, l'imaginaire de la pratique du quotidien qui actualise à chaque instant « des possibles enfouis dans le passé ", selon l'expression de Paul Ricœur ${ }^{48}$.

À Thorshavn, on peut aller en Chine et en Afrique. Le récit "Gamaliels besættelse ", «La possession de Gamaliel », publié en 1960, relate les déboires de Gamaliel Johannesen au cours de l'année 1906, au moment où l'arrivée du câble télégraphique a initié une nouvelle ère dans l'époque médiévale toujours florissante des îles Féroé. En tant qu'inspecteur et homme à tout faire d'un important négociant en produits de la 
pêche, Gamaliel Johannesen dirige entre autres la surveillance des poissonnières. La tâche est éprouvante et l'anarchie du mécontentement social menace de faire irruption à tout moment. Voici ses soucis en discours indirect libre.

Quand elles viennent en grand nombre, surtout, les femmes sont effroyables, et elles peuvent alors à peine être considérées comme des êtres sexués; enfin, elles ne sont plus humaines, au fond, mais quelque chose d'autre, presque une sorte d'insecte. Elles fourmillent, elles bourdonnent, elles piquent, et dans ces situations il n'y a qu'une arme qui vaille : la main ferme.

Tel était l'avis non édulcoré de Gamaliel à ce sujet. Et ces jours-ci la main en question faisait scandaleusement défaut dans les entrepôts de séchage de poissons de la société Rømer. Pas tant à l'est, en Chine, où régnait la justice d'ole Gaillard-deFer, qu'en Afrique, où le Crabe-Main-de-Laine s'apprêtait à laisser tout bonnement tomber. ${ }^{49}$

Au port de ce Port des Féroé, il y a donc aussi l'Afrique et la Chine. Et on peut y voyager sans s'éloigner de Thorshavn, puisque dans la capitale féroïenne ces appellations désignent des lieux spécifiques, selon leurs emplacements sur la carte du marché de la pêche de la ville : au sud ou à l'est. Par cette délocalisation aux îles Féroé, ces noms propres deviennent communs, à savoir les noms communs d'une problématique sociale qui n'est jamais seulement locale : dans l'Afrique et la Chine de Thorshavn, tout comme en Afrique ou en Chine, l'anonymisation du marché frappe le « grand nombre » qui fait l'objet d'une déshumanisation éclair, passant par des sauts on ne peut plus catégoriques : en masse, les femmes sont des existences entomologiques, faisant des bruits sans voix. Elles sont gérées, tant bien que mal, par des hommes réduits à des surnoms désignant leur capacité plus ou moins grande à remplir leur fonction de contrôleur. Gamaliel, lui, tient son nom des Actes des Apôtres dans lesquels le sage éponyme, docteur de la loi, sait faire la part des choses entre toute entreprise de l'homme, par nature destructible, et l'œuvre divine impérissable ${ }^{50}$.

Sur le marché en dehors de Thorshavn qui englobe cette même ville ainsi que l'Afrique et la Chine, l'effacement de la particularité de chacun est universel, à défaut d'être un universalisme. Thorshavn, chez Heinesen, est à la fois inimitable et représentative. Elle a une capacité tout à fait particulière, une capacité qui lui est propre: elle est en mesure de $s e$ faire lieu de tout lieu ${ }^{51}$ - capacité qu'elle partage en principe avec n'importe quel autre endroit «où des hommes naissent et grandissent». Non, le particularisme n'est pas chez l'autre, l'universalisme n'est pas chez nous ${ }^{52}$.

\section{Sortir, arriver}

Dans le Kulturkanon danois, et pour la politique culturelle du retour à l'héritage national qui le porte, le pluriel est (le) singulier : le Canon culturel est censé rappeler et ranimer les œuvres "danoises" les plus notables et richement variées du passé - pas les accomplissements ni les défaillances historiques du royaume, bien sûr -, mais il ne fait que figer négativement son propre présent en immobilisant l'histoire. Pourquoi un auteur majeur de langue danoise comme William Heinesen ne fait-il pas partie de ce Kulturkanon? À cette question il n'y a pas de réponse univoque. Par ailleurs, un jour, Heinesen sortira peut-être définitivement de l'histoire - ou des histoires - de la littérature danoise ${ }^{53}$. Cependant, il fera toujours partie de l'histoire de l'histoire de cette littérature. En ce sens, son éventuelle sortie ne ferait que montrer à quel point il est indissociable de l'histoire de la littérature et de la culture danoises. Pourquoi n'entre-t- 
il donc pas dans la catégorie «Littérature » du Canon culturel danois? Pour les mêmes raisons qu'il y serait entré il y a un bon demi-siècle s'il était venu à l'esprit de qui que ce soit d'établir un Kulturkanon national au cours des décennies suivant la Seconde Guerre mondiale : Féroïen, il a écrit en danois - d'abord dans un danois historiquement colonial, puis dans un danois postcolonial - et ce, tout au long de son parcours officiel d'écrivain, entre 1921 et la fin des années $1980{ }^{54}$. «Mon lien à la langue danoise a été déterminé par le destin ", écrit Heinesen en juillet 1938 à son ami le poète Christian Matras (1900-1988), « ma position en tant qu'auteur féroïen écrivant en danois est une destinée. Ma langue maternelle est très littéralement le danois $»^{55}$. Cette destinée de la langue - destinée romantique nouant l'individu au collectif par le lien intime du lait linguistique maternel - est une destinée coloniale. Dans ses efforts pour dénationaliser l'histoire, William Heinesen n'est jamais allé au-delà de Thorshavn et des îles Féroé. Ainsi, il n'a jamais quitté Copenhague et le Danemark - qui aujourd'hui s'éloignent de lui. Cela dit, la littérature et la culture danoises n'ont pas fini de le laisser partir, tout comme la littérature et la culture féroïennes n'ont pas fini de l'accueillir. Entre Thorshavn et Tórshavn, il y a des limbes littéraires, culturelles et politiques ${ }^{56}$.

\section{NOTES}

1. Voir Danmark og kolonierne : Danmark - En kolonimagt ; Grønland - Den arktiske koloni ; Vestafrika Forterne på Guldkysten; Vestindien - St. Croix, St. Thomas og St. Jan ; Indien - Tranquebar, Serampore og Nicobarerne, Niels Brimnes, Hans Christian Gulløv, Erik Gøbel et al. (dir.), Copenhague, Gad, 2017.

2. Cf. l'introduction générale à l'ouvrage Danmark og kolonierne, "En ny kolonihistorie ». Dans celle-ci, les directeurs de la publication indiquent qu'il n'existe aucune définition « formelle et communément acceptée » de ce qu'est " une colonie ", puis procèdent à l'énumération de quatre critères qui ont déterminé leur perspective : premièrement, le critère chronologique selon lequel seulement les colonies acquises par le « Danemark-Norvège » pendant la période du colonialisme européen à partir de 1500 doivent être considérées; deuxièmement, le critère géographique qui stipule la nécessité d'une « distance considérable » et d'un « détachement » par rapport au « pays mère » $d u$ territoire colonisé ; troisièmement, le critère de la différence au niveau du statut administratif et politique de la colonie vis-à-vis du «centre du pouvoir étatique » colonisateur ; quatrièmement, le critère «thématique »: est «colonie» seulement un territoire dont la population est vue et traitée comme culturellement et ethniquement différente des « colonisateurs » (Grønland - Den arktiske koloni, Hans Christian Gulløv [dir.], op cit., p. 5-6).

3. Kulturkanon, Copenhague, Kulturministeriet \& Politikens Forlag, 2006, p. 220. Toutes les traductions sont les miennes, sauf indication contraire. La mention des « 96 œuvres uniques de l'héritage culturel danois » se trouve sur la quatrième de couverture de l'ouvrage. Peu de temps après la publication du Canon culturel, un huitième domaine, la culture des enfants, a été ajouté à l'univers canonique culturel danois, portant ainsi le nombre d'œuvres incluses à 108. Pour la liste complète, voir le site du Ministère de la culture danois : https://kulturkanon.kum.dk/ (consulté le 9 mars 2020).

4. Voir à ce sujet principalement Benedict Anderson, Imagined Communities: Reflections on the Origin and Spread of Nationalism (Londres, Verso, 1983 ; L'imaginaire national. Réflexions sur l'origine et l'essor du nationalisme, traduit par Pierre-Emmanuel Dauzat, Paris, La Découverte, 1996), Miroslav Hroch, 
Social Preconditions of National Revival in Europe: A Comparative Analysis of the Social Composition of Patriotic Groups Among the Smaller European Nations (Cambridge, Cambridge University Press, 1985) et Eric Hobsbawm, Nations and Nationalism Since 1780. Programme, Myth, Reality (Cambridge, Cambridge University Press, 1990 ; Nations et nationalisme depuis 1780. Programme, mythe, réalité, traduit par Dominique Peters, Paris, Gallimard, 1992).

5. D'Edward W. Said et son ouvrage Orientalism de 1978 (L'Orientalisme. L'Orient créé par l'Occident, traduction de Catherine Malamoud, préface de Tzvetan Todorov, Paris, Seuil, 1980) à Homi K. Bhabha et sa conception de l'hybridité culturelle dans notamment The Location of Culture, paru en 1994 (Les lieux de la culture. Une théorie postcoloniale, traduction de Françoise Bouillot, Paris, Payot, 2007), en passant par Gayatri Chakravorty Spivak et l'étude de la parole « subalterne » (In Other Worlds: Essays in Cultural Politics, Londres, Routledge, 1987; cf. en français par exemple Les subalternes peuvent-elles parler?, traduction de Jérôme Vidal, Paris, Éditions Amsterdam, 2009), entre autres. Sur le passage du " patriotisme étatique » du XVIII siècle au «nationalisme » du $\mathrm{XIX}^{\mathrm{e}}$ dans le contexte spécifique des relations dano-norvégiennes voir l'excellent Skilsmissen. Dansk og norsk identitet før og efter 1814 de Rasmus Glenthøj (Odense, Syddansk Universitetsforlag, 2012). Notons que la première anthologie universitaire d'envergure regroupant d'importants essais - entre autres de Spivak et de Bhabha - relevant des études postcoloniales internationales est parue au Danemark en 2008, en plein milieu du débat sur le canon et sur l'identité nationale nommée danskhed, «danité» (Hans Hauge [éd.], Postkolonialisme, Aarhus, Aarhus Universitetsforlag, coll. « Moderne litteraturteori », 2008).

6. Bien entendu, je me sers ici de l'exemple de Ludvig Holberg vis-à-vis de William Heinesen à cause de l'exemplarité même de son statut: situé au seuil des Lumières, mais encore profondément marqué par le classicisme, Holberg est communément considéré comme le "père de la littérature danoise » et ce, grâce à la richesse qualitative de son travail et l'envergure de domaines et de genres que couvre celui-ci. La citation rappelant cette paternité holbergienne provient d'un ouvrage d'historiographie littéraire récente, Hovedsporet. Dansk litteraturs historie, La trace principale. L'histoire de la littérature danoise, publié chez Gyldendal, la plus prestigieuse maison d'édition du pays, en 2005, la même année qu'ont été constitués les comités de spécialistes chargés d'élaborer le Canon culturel (Hovedsporet. Dansk litteraturs historie, Jens Anker Jørgensen et Knud Wentzel [éd.], Copenhague, Gyldendal, 2005, p. 215). Dans les premières lignes de la «Préface» de cet ouvrage, on lit: "Dans ce livre l'exposé de la littérature danoise se concentre sur ce qui est historiquement représentatif. La raison en est la pression qui s'exerce ces temps-ci contre la tradition nationale et ce, de plusieurs côtés. Cela incite à une accentuation différente et à un tri plus sévère par rapport à ce qu'on a l'habitude de voir dans les histoires de la littérature » (Ibid., p.5). Voilà pourquoi les sagas islandaises et la poésie scaldique - qui ne peuvent en aucun cas être attribuées à une "tradition nationale » au sens strict - entrent telles quelles dans cette histoire littéraire par ailleurs nullement nationaliste, à savoir en tant que représentatives de la culture médiévale scandinave «commune » (Ibid., p. 26). Voilà pourquoi Holberg et son compatriote contemporain Johan Herman Wessel (1742-1785) y entrent également, c'est-à-dire en tant que figures littéraires importantes, voire primordiales de la culture dominante de l'empire danois d'avant 1814, l'année de la cession de la Norvège à la Suède. Et voilà pourquoi des auteurs significatifs de langue danoise du $\mathrm{XX}^{\mathrm{e}}$ siècle, comme les Féroïens Heinesen et Jørgen-Frantz Jacobsen (1900-1938) ou l'Islandais Gunnar Gunnarsson (1889-1975), en sont exclus.

7. Kulturkanon, op. cit., p. 48-49 et 80-81.

8. Ibid., p. 28-29, 100-101, 146-147, 238-239 et 38-39, pour la liste de ces « œuvres ».

9. Ibid., p. 18-19 et 36-37.

10. Parmi les «Critères de sélection» de la catégorie "Architecture», on trouve le suivant: l'œuvre choisie doit être «localisée au Danemark ou à l'étranger» et être le travail «d'un 
architecte danois » (Ibid., p. 8). Qualifier Nicolas-Henri Jardin d'« architecte danois » relève du non-sens, ou bien de l'impérialisme culturel.

11. Voir à ce sujet par exemple Michael Bregnsbo et Kurt Villads Jensen, Det danske imperium. Storhed og fald, Copenhague, Aschehoug, 2004, p. 120-130.

12. Accessible sur le site «danmarkshistorien.dk» de l'Université d'Aarhus: https:// danmarkshistorien.dk/leksikon-og-kilder/vis/materiale/recessen-om-reformationen-af-30oktober-1536/ (consulté le 9 mars 2020).

13. Voir Knud J. V. Jespersen, Historien om danskerne. 1500-2000, Copenhague, Gyldendal, 2007, p. 131-139.

14. Voir l'entrée «Olav Engelbrektsson» dans Norsk biografisk leksikon. Disponible en ligne : https://nbl.snl.no/Olav_Engelbrektsson (consulté le 9 mars 2020).

15. Sur l'histoire, notamment moderne des îles Féroé, voir la récente mise au point de Charlotte Langkilde, Færøerne. En moderne nation fødes, Copenhague, Lindhardt og Ringhof, 2018.

16. $C f$. par rapport à ces brèves remarques sur l'instauration forcée de la Réforme en Norvège, aux îles Féroé et en Islande, Jean-François Battail, Régis Boyer et Vincent Fournier, Les sociétés scandinaves de la Réforme à nos jours, Paris, PUF, 1992, p. 33-41.

17. Signe sûrement plus facile à lire de l'extérieur que de l'intérieur. La conversion imposée à ses frères scandinaves par le royaume de Danemark était « de type colonial », signale par exemple Maurice Gravier en 1984, déjà (Maurice Gravier, Les Scandinaves. Histoire des peuples scandinaves, épanouissement de leur civilisation des origines à la Réforme, Paris, Lidis Brepols, coll. « Histoire ancienne des peuples », 1984, p. 547). L'hésitation par rapport à la catégorisation du royaume de Danemark en tant que colonisateur intra-scandinave - ou intra-nordique - est encore détectable dans l'excellente introduction à l'ouvrage collectif The Postcolonial North. Iceland, Greenland and the Faroe Islands, édité par Lill-Ann Körber et Ebbe Volquardsen - ouvrage dont le titre seul indique par ailleurs, en omettant ce territoire, qu'il ne considère aucunement l'histoire de la domination danoise en Norvège comme une histoire coloniale. Dans cette introduction, les éditeurs signalent d'abord que « $[t]$ he question as to whether the Danish rule over Iceland, Greenland and the Faroe Islands should be labeled as colonialism or rather as the administration of remote provinces or dependencies (sometimes supported by a colonial mentality) is not conclusively answered in this book », puis ajoutent à la page suivante : «Iceland, Greenland and the Faroe Islands are [...] not classified as postcolonial merely because they share a history of foreign rule and oppression, which in different ways affects their present societies. Postcoloniality today is a global phenomenon» (Lill-Ann Körber et Ebbe Volquardsen, «The Postcolonial North Atlantic: An Introduction", in The Postcolonial North. Iceland, Greenland and the Faroe Islands, Körber et Volquardsen [éd.], Berlin, Nordeuropa-Institut der Humboldt-Universität, 2014, p. 18 et 19).

18. Cf. par exemple la notice "Henrik Ibsen : Manuskripter og breve i Det Kongelige Bibliotek » sur le site de la Bibliothèque Royale danoise: http://www5.kb.dk/da/nb/samling/hs/ web_udstil/ibsen.html (consulté le 11 mars 2020).

19. Comme dans l'article « Ny dansk prosa », « Nouvelle prose danoise », que publie le traducteur Kjeld Elfelt dans la revue suédoise Ord och Bild en 1934 (Ord och Bild, 43 ${ }^{\text {ème }}$ année, 1934, Stockholm, P. A. Norstedt \& Söner, p. 661-662). Y apparaît par ailleurs également son compatriote Guðmundur Kamban (1888-1945) (ibid., p. 660-661). La revue est disponible sur le site Project Runeberg : http://runeberg.org/ordochbild/1934/0721.html (consulté le 14 mars 2020).

20. Dansk litteraturhistorie, Gustav Albeck et F. J. Billeskov Jansen (dir.), Copenhague, Gyldendal, $3^{\mathrm{e}}$

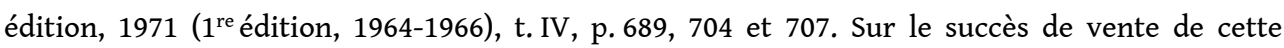
Histoire de la littérature danoise, voir Martin Zerlang, "Litteraturhistorier » dans Dansk litteraturs historie, Klaus P. Mortensen et May Schack (dir), Copenhague, Gyldendal, 2006-09. Cité d'après la version digitalisée: http://denstoredanske.dk/index.php?sideId=477316 (consulté le 14 mars 2020). 
21. Dansk litteraturhistorie, Johan Fjord Jensen et al. (dir.), Copenhague, Gyldendal, t. I-IX, 1984-1985 ; Dansk litteraturs historie, op cit.; Gads danske forfatterleksikon. Litteraturens stemmer, Benedicte Kieler et Klaus P. Mortensen (éd.), Copenhague, Gad, 1999.

22. Maurizio Bettini, Contro le radici. Tradizione, identità, memoria, Bologna, Il Mulino, 2016 ; Contre les racines, traduit par Pierre Vesperini, Paris, Flammarion, coll. "Champs ", 2017, p. 154 et p. 55-56. Voir également à ce sujet l'ouvrage important dirigé par Eric Hobsbawm et Terence Ranger, The Invention of Tradition, Cambridge, Cambridge University Press, 1983 ; L'invention de la tradition, traduit par Christine Vivier, Paris, Amsterdam, 2012. Cf. aussi Marcel Détienne, Comment être autochtone. Du pur Athénien au Français enraciné, Paris, Seuil, 2003.

23. N. F. S. Grundtvig, Det Danske Fiirkløver eller Danskheden partisk betragtet, Copenhague, Den Wahlske Boghandel, 1836, p. VI. Je modernise l'orthographe.

24. L'ouvrage a été traduit par Edgar Quinet en 1834 (Paris, Levraut) et réédité, partiellement, par Marc Crépon en 1991 (Paris, Presses Pocket). Cf. sur les liens et les divergences entre Grundtvig et le philosophe allemand la discussion approfondie de Johannes Adamsen, « Herder og Grundtvig Sonderinger » dans Grundtvig-Studier, $52^{\text {ème }}$ année, n 1, Aarhus, 2001, p. 166-190. Contrairement à Herder, Grundtvig ne regardait pas la réflexion sur le Volksgeist, folkeånden, comme une affaire de philosophie, surtout rationnelle : «l'esprit du peuple» constitue une valeur incontestable et cette valeur est d'emblée sentimentale et nationale. Je reprends dans ce paragraphe certains éléments de mon article "Les douleurs fantômes du XIXe siècle: sur les débâcles historiques danoises à travers la littérature » dans Peuples et pouvoirs en Europe du Nord (2), Virgile Reiter, Pauline Pujo et Gaëlle Reneteaud-Metzger (éd.), dossier de Revue d'histoire nordique, Toulouse, Presses universitaires du Midi, coll. « Méridiennes », 2017, p. 151-163.

25. Dans ces remarques sur la tradition des ballades populaires, l'université humboldtienne et surtout la conception national-romantique de la langue, je me laisse inspirer par l'excellent article « Fra leverpostej til frugtsalat. Tanker om danskhed og sprog » de Frans Gregersen. Voir Hvad er så danskhed, Torben Fledelius Knap, Morten Nielsen et Jacob Pindstrup (éd.), Copenhague, Hovedland, 2005, p.144-162. Cf. au sujet de la disparition de la culture populaire, le travail pionnier de Peter Burke, Popular Culture in Early Modern Europe, New York, Harper \& Row, 1978.

26. Tout au long de son Kampen om sandhederne. Om det kulturelle borgerskabs storhed og fald, Rune Lykkeberg offre une magistrale analyse de ce débat et de son arrière-fond spécifique danois dans l'essor et la chute de la social-démocratie historique et de sa pensée universaliste, pensée qui dans les années 1990-2000 se trouvait impuissante face au retour de ce qu'elle avait elle-même fait tout pour opprimer : l'héritage national-chrétien (Copenhague, Gyldendal, 2008).

27. Voir Marc Augé, Non-lieux. Introduction à une anthropologie de la surmodernité, Paris, Seuil, « La Librairie du XXI" siècle ", 1992.

28. Pour une discussion générale de ces aspects voir par exemple François Chaubet et Laurent Martin, Histoire des relations culturelles dans le monde contemporain, Paris, Armand Colin, coll. «U », 2011, p. 193-269. Au sujet de l'homologation, consulter Maurizio Bettini, op. cit., p. 7 et suivantes. Cf. aussi Marc Augé, op. cit. Dans le débat sur l'uniformisation et l'homologation, on court par ailleurs toujours le risque de surestimer la signification de l'indéniable aplanissement au niveau des produits, des biens et des services culturels mondialisés - y compris, bien sûr, ceux qu'on rangeait autrefois dans le domaine toujours extensible de la Kulturindustrie - en négligeant l'aspect éminemment local de leur accueil, accueil souvent critique et transformateur dans sa manière d'investir sans cesse différemment des objets en apparence pleinement identiques. Je remercie Harri Veivo pour ses remarques à ce sujet. Comme le signale Étienne Helmer, un argument similaire pourrait être avancé vis-à-vis de la conception des non-lieux de Marc Augé : existe-t-il vraiment une carence intrinsèque aux dénommés non-lieux - supermarchés, aéroports... - par rapport à laquelle tout investissement individuel et/ou collectif serait sans aucun effet ? Voir Étienne Helmer, Ici et là. Une philosophie des lieux, Paris, Verdier, 2019, p. 106. 
29. Les lois et les décrets régissant l'exception culturelle au niveau de la communication audiovisuelle sont accessibles sur le site du Conseil Supérieur de l'Audiovisuel. Voir « Qu'appellet-on "l'exception culturelle" ?»: https://clesdelaudiovisuel.fr/Connaitre/Histoire-de-laudiovisuel/Qu-appelle-t-on-l-exception-culturelle (consulté le 24 mars 2020).

30. Il est possible, signale Maurizio Bettini dans ses propos au sujet de la mondialisation dont je me laisse ici inspirer, «que le passé et la tradition reviennent au centre de notre attention parce que c'est là - et dans certains cas, seulement là - que réside le dernier bastion de la différence ». Et à l'auteur d'ajouter : « Nous vivons immergés dans une anthropologie réelle de l'homologation et nous inventons une anthropologie imaginaire de la différence » (Bettini, op. cit., p. 9 et 10 ; l'auteur souligne). Le critique culturel danois Kasper Støvring - un des défenseurs de l'héritage national les plus en vue au pays - offre dans son essai Sammenheengskraft une perspective conservatrice sur ce qui est selon lui l'éminente «force de cohésion » - historique et actuelle - du peuple danois, force de cohésion qui se trouve selon lui aujourd'hui menacée par le multiculturalisme, dont il propose par ailleurs une critique souvent très pertinente, en indiquant entre autres la fonction de rempart national qu'exerce le Canon culturel. Cependant, Støvring néglige de montrer en quoi le débat violent et acerbe sur l'immigration - et ce débat ne constitue évidemment pas juste un exemple quelconque parmi d'autres - témoigne de la présence d'une véritable «force de cohésion » entre les Danois (Voir Kasper Støvring, Sammenhœengskraft, Copenhague, Gyldendal, 2010 [e-pub], p. 147-181; à propos du Kulturkanon, ibid., p. 56-60). Cf. Jean Fischer, «Sammenhængskraft», in Berlingske, Copenhague, 18 juin 2010, https://www.berlingske.dk/ kronikker/sammenhaengskraft (consulté le 24 mars 2020).

31. Cf. l'entrée "après-coup» dans J. Laplanche et J.-B. Pontalis, Vocabulaire de la psychanalyse, Paris, PUF, coll. « Quadrige », 2007 (1967), p. 33-36.

32. Jan Assmann, Das kulturelle Gedächtnis. Schrift, Erinnerung und politische Identität in frühen Hochkulturen, Munich, C. H. Beck, 2005 (1992), p. 119 ; La mémoire culturelle. Écriture, souvenir et imaginaire politique dans les civilisations antiques, traduit par Diane Meur, Paris, Flammarion, 2009). 33. Ce sens originel de fil conducteur en tant que règle constitue bien sûr le fondement de la conception religieuse d'un canon textuel, c'est-à-dire d'un corpus d'écrits considérés comme authentiquement sacrés. Voir par exemple l'entrée «kanon » dans Ordbog over det danske sprog, disponible en ligne : https://ordnet.dk/ods/ordbog?query=kanon (consulté le 6 mai 2020).

34. Kulturkanon, op. cit., p. 5.

35. William Heinesen, Information, Copenhague, 7 janvier 1980. Cité d'après Jógvan Isaksen, Mellem middelalder og modernitet. Omkring William Heinesens prosa, Tórshavn, Amaldus, 2004, p. 7.

36. Claude Lévi-Strauss, La Pensée sauvage, in Lévi-Strauss, Euvres, Paris, Gallimard, coll. "Bibliothèque de la Pléiade ", préface par Vincent Debaene, édition établie par Vincent Debaene, Frédéric Keck, Marie Mauzé et Martin Rueff, 2008, p. 837: «Si les dates ne sont pas toute l'histoire, ni le plus intéressant dans l'histoire, elles sont ce à défaut de quoi l'histoire elle-même s'évanouirait ", écrit l'auteur, un brin provocateur, dans ce célèbre passage de La Pensée sauvage, "puisque toute son originalité et sa spécificité sont dans l'appréhension du rapport de l'avant et de l'après, qui serait voué à se dissoudre si, au moins virtuellement, ses termes ne pouvaient être datés"

37. Voir Langkilde, op. cit., p. 9.

38. Dans son article «The Faroese Rest in the West: Danish-Faroese World Literature between Postcolonialism and Western Modernism », Bergur Rønne Moberg reconsidère ces aspects en les situant dans le contexte de la Weltliteratur revue par la théorie postcoloniale. Suivant cette perspective, l'auteur signale entre autres ceci : « Heinesen's literary space in particular not only concerns cosmopolitan influenced concepts such as contact zones, hybridity, inbetweennness, andzones etc., but is also a critique of European culture and capitalism that challenges the Eurocentric idea of progress » (Bergur Rønne Moberg, "The Faroese Rest in the West: DanishFaroese World Literature between Postcolonialism and Western Modernism ", in Körber et 
Volquardsen, op. cit., p. 189). Même si un tel propos rend l'auteur féroïen pratiquement identique à des écrivains comme Salman Rushdie, Hertha Müller, V. S. Naipaul, Elfriede Jelinek, etc. l'article de Moberg offre une très bonne perspective sur la littérature dano-féroïenne (post)coloniale et ses affinités avec la littérature mondiale, d'un point de vue théorique surtout.

39. William Heinesen, "Belsmanden", in Heinesen, Fortcellinger fra Thorshavn, Copenhague, Gyldendal, 1973, p. 90. Sur le thème de la modernité prenant subitement la relève de l'âge médiéval - thème crucial pour Heinesen -, cf. les considérations de Jógvan Isaksen dans son Mellem middelalder og modernitet. Omkring William Heinesens prosa, considérations qui essentialisent quelque peu cette rupture historique en l'associant fermement au motif excessivement général « du lien indissociable de la vie et de la mort» qu'exprime selon l'auteur la coprésence du « réalisme » et du « mythe » chez Heinesen (Isaksen, op. cit., p. 223 et 235).

40. Pour les citations dans ce paragraphe, voir William Heinesen, «Våd hjemstavn », dans Fortcellinger fra Thorshavn, op. cit., p. 257 ; Det gode håb, Copenhague, Gyldendal, 1964, p. 94 ; et «Småstad og Babel », dans Fortcellinger fra Thorshavn, op. cit., p. 23.

41. $C f$. éventuellement Homi $\mathrm{K}$. Bhabha sur la nécessité de dissoudre - ou de rendre hybride - la traditionnelle opposition binaire du « centre » et de la " périphérie ». Bhabha, op. cit., p. 31-61.

42. William Heinesen, op. cit., p. 13.

43. Pour l'ici et pour le là, je propose de voir Étienne Helmer, op. cit.

44. Au sujet des origines nationales de l'écriture historique et du lien - ou de l'absence de lien entre historiens et anthropologues, voir le pamphlet théorique Comparer l'incomparable de Marcel Detienne, Paris, Seuil, coll. "La librairie du XXI ${ }^{\mathrm{e}}$ siècle », 2000. Mes propos sur la multiplicité inhérente à la localité toujours très locale chez Heinesen sont d'ailleurs inspirés de la notion du «singulier-pluriel» dont se sert Detienne afin de caractériser le «comparatiste " travaillant « entre » histoire et anthropologie (Ibid., p. 42-44).

45. «Nous avons le choix, nous pouvons nous laisser noyer dans les eaux troubles du mystère de la vie ou chercher à rester au-dessus à l'aide de notre raison critique. Le problème dominant de notre temps n'est pas religieux ou national, ni un problème psychologique des profondeurs ou un problème " personnel ». C'est un problème entre hommes, un problème social ». Le poète et éditeur Otto Gelsted (1888-1968) cite ce propos de son ami Heinesen dans un petit essai sur le travail de ce dernier. Voir Gelsted, «William Heinesen og hans værk », dans Gelsted, Goddag liv!, Copenhague, Sirius, 1958, p. 83.

46. Voir à ce sujet Langkilde, op. cit., p. 20-21.

47. Heinesen, op. cit., p. 25 et 116.

48. Chez Ricœur, cette formule touche spécifiquement aux intersections de l'histoire et de la fiction. L'auteur écrit : «Le quasi-passé de la fiction devient [...] le détecteur des possibles enfouis dans le passé effectif. Ce qui "aurait pu avoir lieu" - le vraisemblable selon Aristote - recouvre à la fois les potentialités du passé "réel" et les possibles "irréels" de la pure fiction ». Paul Ricœur, Temps et récit, t. 3, Le temps raconté, Paris, Points, 1991 (1985), p. 347 ; l'auteur souligne.

49. Heinesen, Fortcellinger fra Thorshavn, p. 149-150.

50. Actes des Apôtres 5, 34-39.

51. Cf. Étienne Helmer sur la nécessité de «faire lieu de tout lieu » du « cosmopolite » Diogène le Cynique ; op. cit., p. 94.

52. Voir Michel Agier, La condition cosmopolite. L'anthropologie à l'épreuve du piège identitaire, Paris, La Découverte, 2013, p. 109.

53. Ce jour futur éventuel serait peut-être aussi la date de son accueil définitif dans la littérature des îles Féroé. Cette problématique - qui appartient à une perspective féroïenne - n'entre pas directement dans mon sujet, mais en constitue évidemment la contrepartie. Notons seulement que William Heinesen a été pendant longtemps tenu à l'écart dans l'institution littéraire féroïenne - institution née seulement au XX ${ }^{\mathrm{e}}$ siècle - et que les œuvres de cet auteur féroïen pas féroïen n'ont été traduites qu'au cours des années 1970, la décennie principale, aussi, de la longue 
polémique autour de la candidature possible de l'auteur au prix Nobel de littérature, candidature que retire Heinesen lui-même en 1977 - avant de finalement retirer le retrait dix ans plus tard. Pour une discussion de ces aspects, voir Isaksen, op. cit., p.11-22, et Malan Marnarsdóttir, "Translations of William Heinesen - a Post-colonial Experience », in Körber et Volquardsen, op. cit., p. 195-209.

54. Dans une perspective plus générale, il faut noter que l'inclusion ou l'exclusion d'un auteur d'un canon ne dépend jamais d'un quelconque choix individuel, ni de la qualité esthétique en soi - toujours sujet à débat, bien entendu -, de l'œuvre, voire du contenu idéologique de celle-ci. "[C]anonical forms, the categories of textual appropriation and reproduction in their institutional sites, operate as mechanisms of selection before individuals exercise judgments, of whatever kind ", écrit à ce sujet John Guillory dans son importante contribution au débat sur l'origine et le statut des canons littéraires, Cultural Capital. The Problem of Literary Canon Formation (Chicago et Londres, Chicago University Press, 1994 [1993], p. 123).

55. Heinesen à Matras, le 3 juillet 1938, cité d'après Isaksen, op. cit., p. 19. Par l'expression «très littéralement ", William Heinesen fait implicitement référence à l'origine danoise de sa mère.

56. Des limbes plutôt qu'une « hybridité culturelle » au sens de Homi K. Bhabha. Voir Bhabha, op. cit., p. 36.

\section{RÉSUMÉS}

Dans cet article, je considère le statut de l'auteur féroïen William Heinesen (1900-1991) en relation avec la culture et la littérature (canoniques) danoises : ayant rédigé l'intégralité de son œuvre en danois, cet écrivain majeur scandinave du XXe siècle n'entre pas dans le Kulturkanon officialisé par le Ministère de la culture à Copenhague en 2006. Cependant, il appartient encore à l'histoire de la littérature danoise. Mais pour combien de temps?

Après une première partie consacrée au Canon culturel danois et aux liens entre le royaume du Danemark et ses "dépendances" nordiques depuis l'époque de la Réforme, j'étudie certains éléments décisifs de la dénationalisation culturelle et politique qu'entreprend William Heinesen dans son œuvre en prose. Ainsi, nous verrons en quoi la pensée de la localité universelle dans le travail de l'écrivain - tout aussi fièrement féroïen que résolument antinationaliste - se différencie du romantisme national danois actuel.

In this article, I consider the status of the Faroese writer William Heinesen (1900-1991) in relation to Danish (canonical) culture and literature: having written all of his work in Danish, this major Scandinavian writer of the twentieth century is nowhere to be found in the official Kulturkanon published by the Ministry of Culture in Copenhagen in 2006. However, Heinesen's cuvre still belongs to the history of Danish literature. But for how long will this remain the case?

Following a first section devoted to the Danish Culture Canon and to the links between the Kingdom of Denmark and its Nordic "dependencies" since the time of the Reformation, I'll discuss certain decisive elements of the cultural and political denationalization that William Heinesen undertakes in his prose work. Thus, we will see how the conception of universal locality in the writings of the author - as proudly Faroese as he is resolutely anti-nationalistic - differs from current Danish national romanticism. 
INDEX

Mots-clés : littérature scandinave, Ile Féroé, Heinesen (William), Danemark

Keywords : Scandinavian literature, Faroe Islands, Heinesen (William), Denmark

\section{AUTEUR}

\section{CHRISTIAN BANK PEDERSEN}

Christian Bank Pedersen est maître de conférences, Département d'études nordiques, université de Caen Normandie. Membre de l'EA 4254 ERLIS 